\title{
Collaborative/Active Participation per se Does Not Decrease Anxiety in Breast Cancer
}

\author{
Zsuzsanna KAHÁN, ${ }^{1}$ Katalin VARGA, ${ }^{1}$ Rita DUDÁS, ${ }^{1}$ Tibor NYÁRI, ${ }^{2}$ László THURZÓ ${ }^{1}$ \\ ${ }^{1}$ Department of Oncotherapy, ${ }^{2}$ Department of Medical Informatics, University of Szeged, Szeged, Hungary
}

The information needs of breast cancer patients on their disease, its treatment, the prognosis, and their attitude to decision-making concerning treatment were assessed. One hundred and fifty early and 45 metastatic breast cancer patients were recruited into the study. The amount of information and role in the treatment decision-making process preferred by the patient were independently estimated by the patient and the oncologist, using questionnaires. Information was provided in accordance with the wishes of the patient as perceived by the physician. Test of anxiety was performed before, and one week after the consultation. Most of the patients claimed to anticipate the provision of extensive information and an active role in the decision-making, but real interest during the consultation was found less frequently. The post-consultation anxiety test revealed a significant decrease in situational anxiety; this was not related to the patient's information needs or her attitude to the decision-making concerning treatment. Our study demonstrates that a significant decrease in anxiety may be achieved via a consultation tailored to the needs of the patient. Loading the patient with information and involvement in the decision regarding therapy as much as the patient seems comfortable with lowers distress. (Pathology Oncology Research Vol 12, No 2, 93-101)

Key words: anxiety, early breast cancer, information needs, metastatic breast cancer, treatment decision-making

\section{Introduction}

Increasing efforts are being made to improve the psychosocial care of cancer patients, ${ }^{1}$ including the interaction between the patient and the physician conveying the diagnosis, prognosis and treatment plan. ${ }^{2}$ The treatment guidelines ${ }^{3,4}$ encourage, and civil patient advocate societies demand that breast cancer patients be provided with better information relating to their disease, the necessary treatment and the prognosis, and their active participation during the decision-making process concerning the treatment. The distress-decreasing effect of an active role of the patient during the defining of the treatment strategy has been suggested. ${ }^{5}$ Nonetheless, the conclusions of clinical studies are equivocal: some support ${ }^{6-9}$ the relevance of an enhanced involvement of the patients in surgical or oncological consultations,

Received: Nov 14, 2005; accepted: March 20, 2006

Correspondence: Zsuzsanna KAHÁN, Department of Oncotherapy, University of Szeged, Korányi fasor 12., Szeged, H-6720, Hungary; Phone: 36-62-545406; Fax: 36-62-545922; e-mail: kahan@onko.szote.u-szeged.hu whereas others stress the need for flexible individual care. ${ }^{10-}$ ${ }^{13}$ In our daily practice, we have experienced that patients are not always open to information regarding their illness, and it is often difficult to involve them in the treatment decisionmaking. Accordingly, we decided to study the information needs of patients attending our oncology department. We set out to establish the extent to which the patients wished to participate in the process of treatment decision-making, and to analyze the interactions between the actual role they achieved and other patient- and disease-related factors. Additionally, we studied the relation, if any, between the patients' anxiety and their attitude to information provision and treatment decision-making.

\section{Materials and Methods}

Patients attending their first oncological consultation because of early or metastatic breast cancer were enrolled in the study. Women were ineligible if they were younger than 18 years, suffered from a severe mental or other illness except for breast cancer, had a physical performance status $>$ ECOG 2, or had previously had any other malig- 


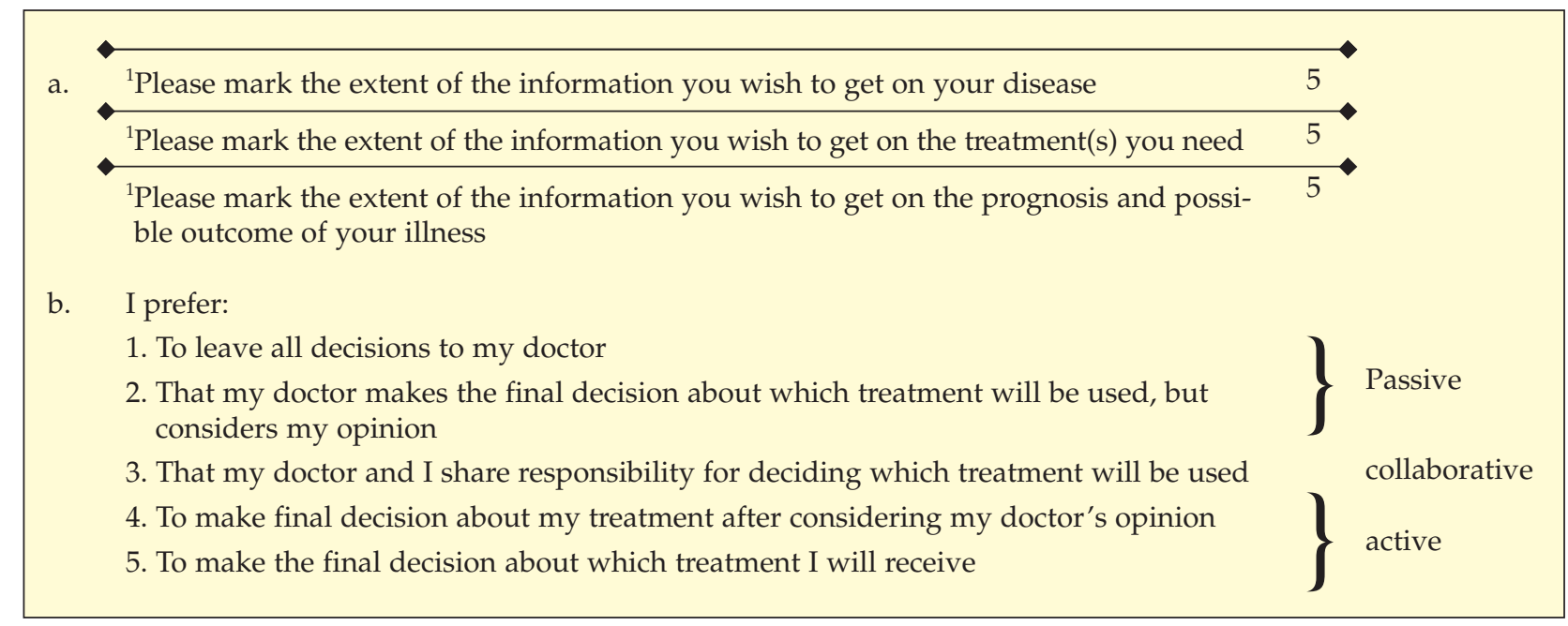

Figure 1. The structure and the evaluation method of the self-questionnaires completed by the patient prior to the oncological consultation, including (a) visual analog scales for assessing the patients' information needs on the disease, the necessary treatments and the prognosis, (b) a list of 5 alternative roles in the treatment decision-making process developed by Wallberg et al. ${ }^{8}$

nancy. Literacy in Hungarian was required. The study had been approved by the Institutional Review Board of the University of Szeged, and all the enrolled patients gave their written informed consent before being registered as participating in the study. One hundred and fifty patients after surgery (early breast cancer cases) and 46 metastatic breast cancer patients were recruited into the study between $01 / 2002$ and $10 / 2004$.

Prior to the consultation, the following steps were performed, guided by the department's mental hygienist (RD): 1. the collection of demographic data (age, partner status, work status, physical performance status, and time elapsed since the first diagnosis of breast cancer); 2. completion of the Spielberger State Anxiety Scale for the estimation of preconsultation anxiety (habitual and situational), ${ }^{14} 3$. completion of a self-questionnaire about the patient's need for information concerning her disease, the necessary treatment, and the prognosis, using visual analog scales; 4. selection of the preferred role from a list of 5 possible alternatives in the treat- ment decision-making process using the tool developed by Degner and Sloan ${ }^{15}$ (Figure 1); 5. listing of questions to be discussed at the consultation by choosing from a given question prompt sheet, or adding new ones (Figure 2).

\begin{tabular}{|c|c|c|}
\hline \multirow[b]{2}{*}{ Question } & \multicolumn{2}{|c|}{ Selected } \\
\hline & $\begin{array}{l}\text { Early BC } \\
(n=150)\end{array}$ & $\begin{array}{c}\text { Metastatic } B C \\
(n=46)\end{array}$ \\
\hline 1. What kind of cancer do I have? & $146(97 \%)$ & $28(61 \%)$ \\
\hline 2. How much is my cancer spread? & $103(71 \%)$ & $33(72 \%)$ \\
\hline 3. What symptoms will the cancer cause? & $111(74 \%)$ & $29(63 \%)$ \\
\hline 4. Will I need any more tests? & $106(71 \%)$ & $31(67 \%)$ \\
\hline 5. What treatment will I need? & $140(93 \%)$ & $41(89 \%)$ \\
\hline $\begin{array}{l}\text { 6. Does the treatment have any side-effects? } \\
\text { If so, what can be done about them? }\end{array}$ & $136(91 \%)$ & $41(89 \%)$ \\
\hline $\begin{array}{l}\text { 7. What may I do or not while having the } \\
\text { treatment? }\end{array}$ & $119(79 \%)$ & $37(80 \%)$ \\
\hline 8. When shall we know if the treatment works? & $129(86 \%)$ & $38(83 \%)$ \\
\hline 9. What effect will my cancer have on my family? & $72(48 \%)$ & $23(50 \%)$ \\
\hline 10. May I work? & $76(51 \%)$ & $25(54 \%)$ \\
\hline 11. Will my sexual life be affected? & $41(27 \%)$ & $10(22 \%)$ \\
\hline 12. Shall I be cured? & $120(80 \%)$ & $37(80 \%)$ \\
\hline 13. What are the chances for the cancer to come back? & $126(84 \%)$ & $31(67 \%)$ \\
\hline $\begin{array}{l}\text { 14. Do members of my family have a greater risk } \\
\text { of getting cancer? }\end{array}$ & $84(56 \%)$ & $21(46 \%)$ \\
\hline $\begin{array}{l}\text { 15. How should I treat myself (diet, supportive groups, } \\
\text { training, social support, psychological help?) }\end{array}$ & 99 (66\%) & $34(74 \%)$ \\
\hline
\end{tabular}

Figure 2. A question prompt sheet adapted from Brown et al. ${ }^{6}$ The frequency of a question having been chosen by the patient with early or metastatic breast cancer $(B C)$ is shown. The most and the least popular questions selected by both groups are highlighted. 
a. 1. The patient does not want to get information at all

2. The patient wants very limited information

3. The patient needs information appropriate for getting an impression only

4. The patient needs a "usual" amount of information

5. The patient wants to have information beyond the "usual” amount

b. 1. The patient wants to leave treatment decision to the doctor

2. The patient wants the doctor to decide but considering the opinion of the patient

3. The patient wants shared decision with the doctor

4. The patient wants to make decision but considering the opinion of the doctor

5. The patient wants to make the decision alone

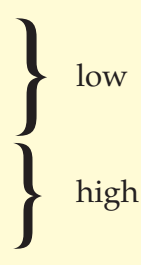

\} passive collaborative active

Figure 3. Evaluation forms for the physician to document the patient's attitude (a) to the information on the disease, treatment and prognosis, respectively, and (b) to treatment decision-making

The consultations were all conducted by the same physician $(\mathrm{ZK})$, who was unaware of the pre-consultation data. During the consultation, the physician, strictly adhering to the criteria of 5 typical levels of information requirements and 5 levels of decision-making involvement (Figure 3), scored the patient's needs by continuously soliciting her preferences. Information on the disease, the need for treatment (medical therapy and/or radiotherapy), possible treatment options, the risk involved in treatment, the prognosis and the benefit of the treatment was provided in accordance with the wishes of the patient as perceived by the physician. All issues and the additional questions were addressed in an open discussion. The outcome of treatment and the prognosis were communicated individually, the extent of which varying considerably: ranging between the minimum necessary information and the numerical expression of risks and benefits, ${ }^{16}$ as required by the patients. A second consultation was offered if the need for a decisional delay was apparent. Brochures on breast cancer, chemotherapy, radiotherapy and diet issues were offered. Finally, a shared treatment decision was made, in which the input from the side of the patient was as much as the patient felt comfortable. The length of the consultations was registered. One week after the last consultation, 97 of the early and 35 of the metastatic breast cancer patients were invited for a second assessment of anxiety by the Spielberger test.

The distributions of the demographic, patient-related and disease-related data in the two groups of patients were analyzed by means of Student's t-test and Fisher exact tests. Cohen's kappa was determined to assess the degree of agreement between the estimations of the patient and the physician on the need for information and the attitude toward the treatment decision. Logistic regression was applied to investigate the relationships between the data overall. The method of logistic regression was used to make predictions when the dependent variable was dichotomous, and the independent variables were continu- ous and/or discrete. The baseline status and post-consultation anxiety status were compared through the Spielberger scores with paired sample t-test. The association between baseline anxiety and the change in anxiety following the consultation was measured via the correlation coefficient.

\section{Results}

The demographic data on the study participants are shown in Table 1. Although a significantly greater proportion of early breast cancer patients lived with a partner and had a better physical performance status than metastatic breast cancer patients, no other difference was found between the two groups (Table 1). The pre-consultation habitual or situational anxiety status did not differ between the early and the metastatic breast cancer patients (Table $2)$. The consultations lasted for $26.3 \pm 0.8$ (10-74) and $28.4 \pm 1.4(10-50)$ minutes for the early and the metastatic breast cancer groups, respectively. The numbers of additional questions raised by the patients for the consultation were $10.9 \pm 0.3(0-15)$ and $10.5 \pm 0.6(0-15)$ in the two groups, respectively. Apart from the issues that were previewed as subjects of the consultation, questions concerning self-care, and especially diet, were the top priorities; the question of sexuality was rated lowest (Figure 1).

In the early breast cancer group $97-98 \%$, and in the metastatic breast cancer group $89-91 \%$ of the patients considered that their information needs were high, but the physician detected real interest much less frequently: 46$79 \%$ and $24-63 \%$ in the early and the metastatic breast cancer groups, respectively (Table 3 ). In both groups, the patients were most interested in the therapy, and least interested in the prognosis (Table 3, Figure 1). There was a high level of discordance between the assessment of the patient and that of the physician as also demonstrated by the low value of the Cohen's $\kappa$ (Table 3 ). 
Table 1. Demographic data of early or metastatic breast cancer patients participating in the study

\begin{tabular}{|c|c|c|c|c|c|c|}
\hline & $\begin{array}{l}\text { Age (year, } \\
\text { mean } \pm S E, \\
\text { range) }\end{array}$ & $\begin{array}{l}\text { Partner- } \\
\text { ship }\end{array}$ & Education & Job & $\begin{array}{c}\text { ECOG Physical } \\
\text { performance status }\end{array}$ & $\begin{array}{c}\text { Time elapsed since } \\
\text { the diagnosis of } B C \\
(\text { days, mean } \pm S E, \text { range })\end{array}$ \\
\hline $\begin{array}{l}\text { Early BC } \\
(\mathrm{n}=150)\end{array}$ & $\begin{array}{l}55.57 \pm 0.85 \\
(28-84)\end{array}$ & $\begin{array}{c}\text { Yes: } \\
113(75 \% \\
\text { No: } \\
37(25 \%)\end{array}$ & $\begin{array}{c}\text { Primary school: } \\
53(35 \%) \\
\text { Secondary school: } \\
72(48 \%) \\
\text { College or higher: } \\
25(17 \%)\end{array}$ & $\begin{array}{c}\text { Laborer: } \\
81(54 \%) \\
\text { Entrepreneur: } \\
11(7 \%) \\
\text { Intellectual worker: } \\
54(36 \%) \\
\text { Unemployed: } \\
4(3 \%)\end{array}$ & $\begin{array}{c}0: 75(50 \%) \\
1: 64(43 \%) \\
2: 11(7 \%)\end{array}$ & $\begin{array}{l}70.2 \pm 3.6 \\
(20-365)\end{array}$ \\
\hline $\begin{array}{l}\text { Metastatic } \\
\text { BC }(n=46)\end{array}$ & $\begin{array}{l}58.15 \pm 1.53 \\
\quad(30-81)\end{array}$ & $\begin{array}{c}\text { Yes: } \\
24(52 \%) \\
\text { No: } \\
22(48 \%)\end{array}$ & $\begin{array}{c}\text { Primary school: } \\
22(48 \%) \\
\text { Secondary school: } \\
18(39 \%) \\
\text { College or higher: } \\
6(13 \%)\end{array}$ & $\begin{array}{c}\text { Laborer: } \\
27(59 \%) \\
\text { Entrepreneur: } \\
3(6 \%) \\
\text { Intellectual worker: } \\
16(35 \%) \\
\text { Unemployed: } \\
0(0 \%)\end{array}$ & $\begin{array}{l}\text { 0: } 16(35 \%) \\
\text { 1: } 20(43 \%) \\
\text { 2: } 10(22 \%)\end{array}$ & $\begin{array}{c}1564.7 \pm 262.2 \\
(60-9490)\end{array}$ \\
\hline$p$ & 0.144 & 0.005 & 0.341 & 0.879 & 0.019 & NA \\
\hline
\end{tabular}

$\mathrm{BC}$, breast cancer; NA, not applicable

In the pre-consultation test in the early breast cancer group, $48 \%$ and $5 \%$ of the patients expressed a desire for a collaborative or an active role in the treatment decisionmaking, respectively, whereas the oncological consultation revealed that only $9 \%$ had achieved a collaborative role, and 5\% an active role; the others were passive (Table 4 ). In the metastatic group, $54 \%$ of the patients reported a preference for a passive role, $41 \%$ preferred a collaborative role, and $5 \%$ preferred an active role. In reality, 54\% and $25 \%$ demonstrated a passive and a collaborative attitude, respectively, while the proportion of actively participating patients was $21 \%$ (Table 4). Nonetheless, the patient's decision-making attitude could not be correctly judged in 23 early and 2 metastatic breast cancer cases by the physician. There was a high level of disagreement between the perceived and the actual participation of the patients in the treatment decision-making as indicated by the low Cohen's $\kappa$ (Table 4).

We investigated whether the need for information regarding the disease, the treatment and the prognosis, or the role in the treatment decision-making (as perceived by the patient or the physician) were related with each other or with the patients' characteristics, i.e. age, partner status, the level of education, the work status, the ECOG status, the time elapsed since the first diagnosis, and the pre-consultation anxiety level. First, we analyzed the data in a logistic regression model, as screening. In general, among early breast cancer patients, significantly higher need of information was found at a younger age, as assessed by both the patient and the physician; this greater interest favored significantly greater number of additional questions, too (Table 5). There was a strong association between the concurrent interest in the information on the

Table 2. Anxiety status of early and metastatic breast cancer patients as measured by the Spielberger test at the time of the consultation

\begin{tabular}{lcc}
\hline & Anxiety score, habitual (mean \pm SE, range) & Anxiety score, situational (mean \pm SE, range) \\
\hline Early BC $(\mathrm{n}=150)$ & $44.15 \pm 0.87(22-77)$ & $48.39 \pm 0.99(22-77)$ \\
\hline Metastatic BC $(\mathrm{n}=46)$ & $46.30 \pm 1.51(27-70)$ & $49.02 \pm 1.54(28-70)$ \\
\hline$p$ & 0.226 & 0.754 \\
\hline
\end{tabular}

$\mathrm{BC}$, breast cancer 
Table 3. Information needs regarding the disease, treatment and prognosis of the early and the metastatic breast cancer patients as estimated by the patient or the physician. The proportional agreement between their estimations and Cohen's $\kappa$ are shown.

\begin{tabular}{|c|c|c|c|c|c|c|c|}
\hline \multirow[t]{2}{*}{ Information need } & & \multicolumn{2}{|c|}{ Disease } & \multicolumn{2}{|c|}{ Treatment } & \multicolumn{2}{|c|}{ Prognosis } \\
\hline & & Low & High & Low & High & Low & High \\
\hline \multirow[t]{4}{*}{ Early BC } & Patient & $5(3 \%)$ & $145(97 \%)$ & $3(2 \%)$ & $147(98 \%)$ & $3(2 \%)$ & $147(98 \%)$ \\
\hline & Physician & $48(32 \%)$ & $102(68 \%)$ & $32(21 \%)$ & $117(79 \%)$ & $81(54 \%)$ & $68(46 \%)$ \\
\hline & Agreement & $1 \%$ & $66 \%$ & $1 \%$ & $77 \%$ & $1 \%$ & $45 \%$ \\
\hline & $\kappa$ & \multicolumn{2}{|c|}{0.016} & \multicolumn{2}{|c|}{0.021} & \multicolumn{2}{|c|}{0.009} \\
\hline \multirow[t]{4}{*}{ Metastatic BC } & Patient & $5(11 \%)$ & $41(89 \%)$ & $4(9 \%)$ & 42 (91\%) & $5(11 \%)$ & $41(89 \%)$ \\
\hline & Physician & $24(52 \%)$ & $22(48 \%)$ & $17(37 \%)$ & $29(63 \%)$ & $35(76 \%)$ & $11(24 \%)$ \\
\hline & Agreement & $9 \%$ & $46 \%$ & $6 \%$ & $61 \%$ & $11 \%$ & $24 \%$ \\
\hline & $\kappa$ & \multicolumn{2}{|c|}{0.117} & \multicolumn{2}{|c|}{0.169} & \multicolumn{2}{|c|}{0.074} \\
\hline
\end{tabular}

BC, breast cancer

treatment and the prognosis as estimated by the patient $(<0.001)$ or the three different aspects (disease, treatment, prognosis) as assessed by the physician $(\mathrm{p}<0.001)$. On the patient's side there were significant associations between the wish of an active/collaborative attitude to treatment decisionmaking and a high need of information on the disease and the necessary treatments $(\mathrm{p}=0.005$ and $\mathrm{p}=0.016$, respectively, Table 5).

In the metastatic group, also, young age favored higher information need on treatment $(\mathrm{OR}=0.84, \mathrm{p}=0.030,95 \%$ CI: $0.72-0.98)$ and prognosis $(\mathrm{OR}=0.89, \mathrm{p}=0.057,95 \%$ CI: $0.79-1.00)$, as anticipated by the patient, but no such association was found with these parameters assessed by the physician. A lower interest on treatment was found by the physician when habitual anxiety was higher $(\mathrm{OR}=0.93, \mathrm{p}=0.053,95 \% \mathrm{CI}: 0.87$ 1.00). Significant associations were demonstrated between the simultaneous preferences of high knowledge about the disease, the treatment and the prognosis as declared by the patient, and between the interest of information on the disease and the treatment, as experienced by the physician $(\mathrm{p}=0.015)$.

We further studied whether the attitude to treatment decision-making is related to the characteristics of the patient or the disease. In the early breast cancer group, the wish of manifesting a collaborative role by the patient favored a significantly younger age $(p=0.009)$. Those patients who showed an active role during the consultation were younger, however, this trend did not reach statistical significance $(\mathrm{p}=0.061)$. The length of the consultation was significantly longer if the patient achieved a collaborative role $(\mathrm{p}=0.029)$. No such associations could be verified in the metastatic group. The role in treatment decision-making did not correlate with any of the other parameters related to the patient or the disease.

In 97 consecutive early and 35 consecutive metastatic breast cancer patients a post-consultation anxiety test was

Table 4. Preferred (patient) and assumed (as judged by the physician) attitude of early and metastatic breast cancer patients to treatment decision making. The proportional agreements between their assessments and Cohen's $\kappa$ values are indicated.

\begin{tabular}{llccc}
\hline Role in treatment decision & Passive & Collaborative & Active \\
\hline Early BC & Patient & $71(47 \%)$ & $72(48 \%)$ & $7(5 \%)$ \\
\cline { 2 - 5 } & Physician & $110(86 \%)$ & $11(9 \%)$ & $6(5 \%)$ \\
\cline { 2 - 5 } & Agreement & $46 \%$ & $6 \%$ & $1 \%$ \\
\cline { 2 - 5 } & $\kappa$ & $25(54 \%)$ & $19(41 \%)$ & $2(5 \%)$ \\
\hline \multirow{2}{*}{ Metastatic BC } & Patient & $24(54 \%)$ & $11(25 \%)$ & $9(21 \%)$ \\
\cline { 2 - 5 } & Physician & $35 \%$ & $11 \%$ & $2 \%$ \\
\cline { 2 - 5 } & Agreement & & 0.112 & \\
\cline { 2 - 5 } & $\kappa$ & & &
\end{tabular}

BC, breast cancer 
Table 5. Overall dependence of high information needs, as assessed by the patient or the physician, on the age of the patient and the number of additional questions asked by the early breast cancer patients. Although all variables have been included in the logistic regression model, only the statistically significant associations are shown.

\begin{tabular}{|c|c|c|c|c|c|c|c|}
\hline & \multirow[t]{2}{*}{$\begin{array}{l}\text { Information } \\
\text { type }\end{array}$} & \multicolumn{3}{|c|}{$\begin{array}{c}\text { Information needs assessed } \\
\text { by the patient }\end{array}$} & \multicolumn{3}{|c|}{$\begin{array}{c}\text { Information needs assessed } \\
\text { by the physician }\end{array}$} \\
\hline & & OR & $p$ & $95 \%$ CI & $O R$ & $p$ & $95 \%$ C \\
\hline \multirow[t]{3}{*}{ Older age } & Disease & 0.86 & 0.014 & $0.77-0.97$ & 0.96 & 0.042 & 0.93-0.99 \\
\hline & Treatment & 0.87 & 0.054 & $0.76-1.01$ & 0.94 & 0.004 & $0.90-0.98$ \\
\hline & Prognosis & 0.85 & 0.032 & $0.73-0.98$ & & NS & \\
\hline \multirow[t]{3}{*}{ Additional questions } & Disease & 1.28 & 0.036 & $1.01-1.62$ & 1.20 & 0.001 & $1.08-1.32$ \\
\hline & Treatment & 1.38 & 0.044 & $1.01-1.88$ & 1.13 & 0.023 & $1.02-1.21$ \\
\hline & Prognosis & 1.45 & 0.027 & $0.04-2.02$ & & NS & \\
\hline \multirow{2}{*}{$\begin{array}{l}\text { The patient's active role } \\
\text { as assessed by the patient }\end{array}$} & Treatment & & NS & & 1.61 & 0.016 & $1.10-2.36$ \\
\hline & Disease & & NS & & 1.60 & 0.005 & $1.15-2.22$ \\
\hline
\end{tabular}

obtained. A significant decrease of situational anxiety in both the early and the metastatic breast cancer groups was found $(\mathrm{p}=0.0001$ and $\mathrm{p}=0.024$, respectively) (Table 6). Then, we performed a multiple logistic regression analysis to find out whether the level of anxiety, or the decrease of anxiety one week after the consultation are in association with the information needs, attitude to treatment decisionmaking or any of the other variables of the patient. No such associations could be verified (data not shown). Nonetheless, a significant negative correlation was detected between the level of habitual anxiety and the decrease in situational anxiety after the consultation with the physician among early breast cancer patients $(p=0.006, r=-0.277)$. In

Table 6. Change of anxiety status in early and metastatic breast cancer: Spielberger scores before (\#1) and 1 week after (\#2) the last consultation tailored to the needs of the patient as perceived by the physician

\begin{tabular}{llcc}
\hline & \multicolumn{3}{c}{ Anxiety scores $($ mean \pm SE, range) } \\
\cline { 2 - 4 } & \multicolumn{4}{c}{ Habitual } & Situational \\
\hline Early BC $(n=97)$ & $\# 1$ & $44.15 \pm 1.09(22-77)$ & $47.96 \pm 1.17(22-77)$ \\
\cline { 2 - 4 } & $\# 2$ & $44.07 \pm 0.91(21-63)$ & $43.59 \pm 1.19(22-69)$ \\
\cline { 2 - 4 } & $p$ & 0.915 & 0.0001 \\
\hline Metastatic BC (n=35) & $\# 1$ & $46.94 \pm 1.83(27-70)$ & $48.68 \pm 1.81(28-70)$ \\
\cline { 2 - 4 } & $\# 2$ & $45.6 \pm 1.91(28-72)$ & $44.68 \pm 2.22(27-78)$ \\
\cline { 2 - 4 } & $p$ & 0.227 & 0.024 \\
\hline
\end{tabular}

$\mathrm{BC}$, breast cancer contrast, in metastatic breast cancer patients, a significant positive correlation was found between these parameters $(\mathrm{p}=0.049, \mathrm{r}=0.336)$. In the early breast cancer group, the decrease in situational anxiety was significantly greater in women without a partnership than those with a partner $(p=0.022)$. No such relationship was found among the metastatic cases.

\section{Discussion}

The information requirements of patients, and the degree they participate in treatment decision making vary in different countries according to cultural, traditional, legal and economic differences. ${ }^{1,6-13,17-35}$ The patients' expectations also depend on the type of the disease, ${ }^{15,20}$ or the type of the malignancy. ${ }^{13,15,19,25}$ Most of the literature data on the attitude of breast cancer patients towards being informed, and participation in treatment decision come from Canada, ${ }^{15,17,18,26,32}$ the US, ${ }^{7,10,25,27-31,34}$ Australia, ${ }^{6,9,21,22,33}$ or other Western countries, $8,12,13,19,20,23,24,35,36$ while, to our best knowledge, no such data have been published on Central-European patients.

We found that the majority of our patients, irrespective of the stage of the cancer, estimated her information needs higher than valued by the physician. The women were most open to questions related to therapy, both as scored by the physician during the consultation, and as indicat- 
ed by the question prompt sheet. The patients were the least interested in prognosis. This finding accords with those of Brown et al, ${ }^{6}$ who demonstrated that although interest in prognosis may be increased by the use of a question prompt sheet exposing prognosis, but treatment-related issues are the priority for the patients. In a Swedish study, breast cancer patients after surgery were interviewed for their information needs and preferences. ${ }^{8}$ Patients ranked items related to prognosis (chances of cure, disease stage) the highest. This difference between their and our or others' results may be explained by the differences in study design. First, the Swedish trial gave the patients' assumptions only, and second, most of the patients were already having certain informations, as being after the first consultation. Australian patients with metastatic cancer, especially those with a relatively better prognosis, showed a high need of detailed prognostic information. ${ }^{9,33}$ In our study, in the metastatic groups prognosis was valued, both by the patient and the doctor, as even less important than in the early stage group. In fact, communicating prognosis to metastatic cancer patients is especially difficult, and requires considerable resources from both the patients and the doctors. ${ }^{33}$ Most of our metastatic breast cancer patients failed to demand and accept this kind of information. We think that the fear of knowledge of prognosis represents denial on one hand, but is also related to the lower level of self-consciousness and self-determination of this patient population compared to the Australians. In patients with various cancers, Cassileth et al. found that especially those who were younger, white, better educated, and whose disease was more recently diagnosed, sought detailed informations. ${ }^{25}$ Our data are consistent with these findings: the level of information needs both as perceived by the patient and as found by the doctor was significantly higher at younger age.

In our study, the proportion of the early breast cancer patients who voiced the preference of a collaborative/ active role in the treatment decision-making process was far greater $(53 \%)$ than judged by the doctor $(14 \%)$. In a similar study, $89 \%$ of the American patients preferred a collaborative/active role, and $80 \%$ manifested it. ${ }^{31}$ In a Swedish study, $66 \%$ of the breast cancer patients preferred to leave the treatment decision to the doctor. ${ }^{8}$ In a British study this proportion was $52 \% .{ }^{19}$ Our results were similar: the majority of both the early and the metastatic breast cancer patients played a passive role in treatment decision during the consultation. Bilodeau et al. experienced that $43 \%$ of early breast cancer patients preferred, and $57 \%$ assumed a passive role in treatment decisionmaking, and only half of the patients who anticipated a collaborative role, could manifest it during the consultation. ${ }^{26}$ This tendency was especially true for older women. The conclusion was made that women who wanted collaborative roles in treatment decision-making, experienced diffi- culties in achieving it. ${ }^{26}$ Among Chinese women, 59\% wanted a shared decision-making for surgery, and $80 \%$ succeeded to participate as much as desired; older age predicted a passive role. ${ }^{24}$ Maly et al. found that active decision-making on the type of breast surgery among women older than 55 years did not depend on age, but was promoted by special solicitation of the patients' preferences. ${ }^{28}$ Among American women, higher education was significantly related to the patient's activity. ${ }^{34}$ We could not verify an association between the role undertaken in treatment decision-making and any of the patient-related data other than age: those early breast cancer patients who played an active role during the consultation were younger. Interestingly, although the distribution of the 3 main attitude types in treatment decision-making preferred by our metastatic patients was similar to that in the early breast cancer patient group, during the consultation, relatively more metastatic cancer patients played an active role. This result accords with that of Bruera et al., ${ }^{31}$ and may be due to the greater knowledge about different treatment modalities because of former experience with therapies.

With the aim of improving the quality of consultations with breast cancer patients, there has been much endeavor to alleviate information giving and perception. Thus, information tools, like a breast cancer CD-ROM,${ }^{36}$ a breast cancer decision board ${ }^{17,18}$ and a pre-consultation intervention session ${ }^{29}$ were successfully applied. We used a question prompt sheet developed by Brown et al., ${ }^{6}$ which helped the patients to get prepared for the consultation. We did not provide the patients with any pre-consultation written material, but offered it after the visit: some of the patients asked for brochures on breast cancer, chemotherapy, radiotherapy or diet, while others refused them.

Another way to improve patient-physician communication is to educate physicians to conform to the patients' needs, and to learn effective and sensitive communication skills. It has proved useful to specially train clinicians for adjusting to different patient attitudes. In older patients, a better patientphysician communication associated with greater satisfaction with care was more often initiated by surgical oncologists and breast-specialists than by other surgeons. ${ }^{30}$ We believe that psychooncological care, during all over the treatment process, is also of higher level in specialized breast units. ${ }^{37}$

Among British breast cancer patients, those who were offered a choice of surgical treatment, showed less depression than those who were not. ${ }^{5}$ In a pilot study in France, the majority of breast cancer patients participating in the treatment choice (surgery and chemotherapy) generated anxiety, which has been attributed to the unusualness of such practice in France. ${ }^{23}$ The patient's perception regarding choice of adjuvant therapy in breast cancer in general does not seem to have an impact on long-term quality of life (QOL) or satisfaction. ${ }^{12}$ On the other hand, those patients who had a choice but were not treated with 
chemotherapy, had a lower QOL. It was concluded that in cases when the treatment decision has potential consequences for the chance of survival, choice may impair QOL. ${ }^{12}$ In breast, head and neck cancer and Hodgkin's' disease patients, greater information needs related to higher level of anxiety, depression and psychological complaints. ${ }^{13}$ In a retrospective analysis, patients receiving less detailed information had significantly higher satisfaction with the consultation. ${ }^{32}$ The conclusion was drawn that more emphasis should be placed on soliciting patient preferences for information and decision-making involvement, and tailoring both to the needs of the individual patient. ${ }^{32}$ In a clinical study involving 366 cancer cases, patient satisfaction was primarily related to the perception of the patient's addressed needs by the physician. ${ }^{11}$

The main outcome of our study is the demonstration of a significant decrease in anxiety as a consequence of a consultation tailored to the needs of the patient. In other words, the assertive attitude of the oncologist toward the patient, by means of loading her with information and involvement in the decision regarding therapy as much as the patient seems comfortable with, lowers distress. The presence or the magnitude of the amelioration of anxiety did not correlate with the information needs or the role achieved by the patient in therapy decision-making. These results contradict the assumption that activity manifested by the patient during the consultation, either by requiring information or overtaking therapy decision, would per se decrease anxiety raised by breast cancer at an early or an advanced stage. ${ }^{5}$ At the same time our data confirm the commendations that for the optimal result, an interacting consultation with a permanent monitoring of the needs of the individual patient is required..$^{10,11,27,28,31,32}$

The attitude of breast cancer patients toward the disease and the treatment may vary in different countries. It is mandatory to apply such practice that optimally meets their real requirements and preferences. This process may help in adjusting to the situation, and contribute to the decrease of psychological distress.

\section{Acknowledgements}

The authors are grateful to Professor Sándor Eckhardt for his useful advices about the manuscript.

\section{References}

1. Holland JC: IPOS Sutherland Memorial Lecture: an international perspective on the development of psychosocial oncology: overcoming cultural and attitudinal barriers to improve psychosocial care. Psychooncology 13: 445-459, 2004

2. Ruckdeschel JC, Blanchard CG, Albrecht T: Psychosocial oncology research. Where we have been, where we are going, and why we will not get there. Cancer 74(suppl 4): S1458S1463, 1994
3. The Steering Committee on Clinical Practice Guidelines for the Care and Treatment of Breast Cancer. A Canadian consensus document. CMAJ 158(suppl 3): S3-S64, 1998

4. Coates A: Management of early breast cancer: An Australian consensus report. Oncology 52: 82-85, 1995

5. Fallowfield LJ, Hall A, Maguire GP, et al: Psychological outcomes of different treatment policies in women with early breast cancer outside a clinical trial. BMJ 301: 575-580, 1990

6. Brown RF, Butow PN, Dunn SM, et al: Promoting patient participation and shortening cancer consultations: a randomised trial. Br J Cancer 85: 1273-1279, 2001

7. Siminoff LA, Ravdin P, Colabianchi $N$, et al: Doctor-patient communication patterns in breast cancer adjuvant therapy discussions. Health Expect 3: 26-36, 2000

8. Wallberg B, Michelson $H$, Nystedt $M$, et al.: Information needs and preferences for participation in treatment decisions among Swedish breast cancer patients. Acta Oncol 39: 467-476, 2000

9. Hagerty RG, Butow PN, Ellis PA, et al: Cancer patient preferences for communication of prognosis in the metastatic setting. J Clin Oncol 22: 1721-1730, 2004

10. Bruera E, Sweeney $C$, Calder $K$, et al: Patient preferences versus physician perceptions of treatment decisions in cancer care. J Clin Oncol 19: 2883-2885, 2001

11. Blanchard CG, Labrecque MS, Ruckdeschel JC, et al: Physician behaviors, patient perceptions, and patient characteristics as predictors of satisfaction of hospitalized adult cancer patients. Cancer 65: 186-192, 1990

12. Jansen SJ, Otten W, van de Velde CJ, et al: The impact of the perception of treatment choice on satisfaction with treatment, experienced chemotherapy burden and current quality of life. Br J Cancer 91: 56-61, 2004

13. Mesters I, van den Borne B, De Boer M, et al: Measuring information needs among cancer patients. Patient Educ Cons 43: 253-262, 2001

14. Spielberger $C D$ : Manual for the state trait anxiety inventory (Form Y). Consulting Psychologists Press, Palo Alto, CA, 1983

15. Degner LF, Sloan JA: Decision making during serious illness: what role do patients really want to play? J Clin Epidemiol 45: 941-950, 1992

16. Ravdin PM, Siminoff LA, Davis GJ, et al: Computer program to assist in making decisions about adjuvant therapy for women with early breast cancer. J Clin Oncol 19: 980-991, 2001

17. Whelan T, Sawka C, Levine M, et al: Helping patients make informed choices: a randomized trial of a decision aid for adjuvant chemotherapy in lymph node-negative breast cancer. J Natl Cancer Inst 95: 581-587, 2003

18. Whelan T, Levine $M$, Willan A, et al: Effect of a decision aid on knowledge and treatment decision making for breast cancer surgery: a randomized trial. JAMA 292: 435-441, 2004

19. Beaver K, Bogg J, Luker KA: Decision-making role preferences and information needs: a comparison of colorectal and breast cancer. Health Expect 2: 266-276, 1999

20. Beaver $K$, Luker $K A$, Owens $R G$, et al: Treatment decision making in women newly diagnosed with breast cancer. Cancer Nurs 19:8-19, 1996

21. Butow PN, Dunn SM, Tattersall MHN, et al: Patient participation in the cancer consultation: evaluation of a question prompt sheet. Ann Oncol 5: 199-204, 1994

22. Butow PN, Kazemi JN, Beeney LJ, et al.: When diagnosis is cancer. Patient communication experiences and preferences. Cancer 77: 2630-2637, 1996

23. Moumjid N, Carrere MO, Charavel M, et al: Clinical issues in shared decision-making applied to breast cancer. Health Expect 6: 222-227, 2003 
24. Lam W, Fielding $R$, Chan $M$, et al: Participation and satisfaction with surgical treatment decision-making in breast cancer among Chinese women. Breast Cancer Res Treat 80: 171-180, 2003

25. Cassileth BR, Zupkis RV, Sutton-Smith K, et al: Information and participation preferences among cancer patients. Ann Int Med 92:832-836, 1980

26. Bilodeau BA, Degner LF: Information needs, sources of information, and decisional roles in women with breast cancer. Oncol Nurs Forum 23:691-696, 1996

27. Johnson JD, Roberts CS, Cox CE, et al: Breast cancer patients' personality style, age, and treatment decision making. J Surg Oncol 63:183-186, 1996

28. Maly RC, Umezawa Y, Leake B, et al: Determinants of participation in treatment decision-making by older breast cancer patients. Breast Cancer Res Treat 85: 201-209, 2004

29. Sepucha KR, Belkora JK, Tripathy D, et al: Building bridges between physicians and patients: results of a pilot study examining new tools for collaborative decision making in breast cancer. J Clin Oncol 18: 1230-1238, 2000

30. Liang W, Burnett CB, Rowland $J H$, et al: Communication between physicians and older women with localized breast cancer: implication for treatment and patient satisfaction. J Clin Oncol 20: 1008-1016, 2002
31. Bruera E, Willey JS, Palmer JL, et al: Treatment decisions for breast carcinoma: patient preferences and physician perceptions. Cancer 94: 2076-2080, 2002

32. Leighl N, Gattellari M, Butow P, et al: Discussing adjuvant cancer therapy. J Clin Oncol 19: 1768-1778, 2001

33. Butow PN, Dowsett $S$, Hagerty $R$, et al: Communicating prognosis to patients with metastatic disease: what do they really want to know? Support Care Cancer 10: 161-168, 2002

34. Janz NK, Wren PA, Copeland LA, et al: Patient-physician concordance: preferences, perceptions, and factors influencing the breast cancer surgical decision. J Clin Oncol 22: 3091-3098, 2004

35. Protiere $C$, Viens $P$, Genre D, et al: Patient participation in medical decision-making: a French study in adjuvant radiochemotherapy for early breast cancer. Ann Oncol 11: 39-45, 2000

36. Molenaar S, Sprangers MA, Rutgers EJ, et al: Decision support for patients with early-stage breast cancer: effects of an interactive breast cancer CDROM on treatment decision, satisfaction, and quality of life. J Clin Oncol 19: 1676-1687, 2001

37. EUSOMA Position Paper. The requirements of a special breast unit. Eur J Cancer 36: 2288-2293, 2000 